\title{
Marine boundary layer over the subtropical southeast Pacific during VOCALS-REx - Part 2: Synoptic variability
}

\author{
D. A. Rahn and R. Garreaud \\ Departamento de Geofísica, Universidad de Chile, Santiago, Chile \\ Received: 6 November 2009 - Published in Atmos. Chem. Phys. Discuss.: 7 December 2009 \\ Revised: 19 April 2010 - Accepted: 30 April 2010 - Published: 18 May 2010
}

\begin{abstract}
In the second part of this work we study the day-to-day variability of the marine atmospheric boundary layer (MBL) over the subtropical southeast Pacific using primarily results from a numerical simulation that covered the whole VOCALS-REx period (October-November 2008). In situ and satellite-derived observations of the MBL height in the offshore region indicate rapid, significant variations (from $500 \mathrm{~m}$ to $1700 \mathrm{~m}$ a.s.l. over a few days) during October. These MBL changes are connected with the passage of midlatitude troughs that altered the large-scale environment over the VOCALS-REx region. In contrast, the synoptic forcing and MBL changes were less prominent during November. Modelled and observed MBL depth at Point Omega $\left(20^{\circ} \mathrm{S}\right.$, $85^{\circ} \mathrm{W}$ ) compare quite well during October (but the simulation is on average $200 \mathrm{~m}$ lower) while in November the simulation does not perform as well.

In the prognostic local MBL height equation the height change, the horizontal MBL height advection, and the large scale vertical velocity at MBL top are calculated explicitly from the simulation. The entrainment velocity is calculated as the residual of the other terms in the equation. While the vertical velocity and residual terms are opposing and generally have the largest magnitude on average, it is the variability in the advection that explains most of the large changes in the MBL depth. Examination of several cases during VOCALS-REx suggests that the advective term is in turn largely controlled by changes in wind direction, driven by midlatitude activity, acting on a MBL that generally slopes down toward the coast. In one phase, the subtropical anticyclone is reinforced and extends toward the Chilean coast, leading to easterly wind that advects low MBL heights from the coast as far as Point Omega. The opposite phase occurs after the passage of an extratropical cyclone over southern Chile, leading to southwesterly wind that advects a deeper MBL towards subtropical latitudes.
\end{abstract}

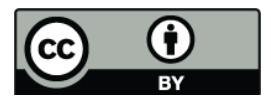

Correspondence to: D. A. Rahn (darahn@gmail.com)

\section{Introduction}

Large scale subsidence dominates over the subtropical southeast Pacific (SEP) resulting in a strong inversion above a well-mixed marine atmospheric boundary layer (MBL). The MBL generally deepens offshore, but the actual height can vary considerably at synoptic scales (Wood and Bretherton, 2004). The depth of the MBL is related to both small scale (e.g., turbulence) and large scale (e.g., variations in synoptic subsidence) phenomena. Local change in MBL depth can be attributed to the vertical velocity at the top of the MBL, entrainment velocity, and horizontal advection (Schubert et al., 1979). MBL characteristics have been examined on a variety of scales. A mixed layer model has been used to investigate local MBL processes (e.g., Lilly, 1968; Caldwell et al., 2005). This model has also been applied within a Lagrangian framework to examine column changes in the MBL over time (Liu et al., 1992; Lewis, 2007). For much larger scales, Wood and Bretherton (2004) examined the mean state of each of the terms in the prognostic MBL depth equation using a synthesis of satellite and reanalysis data over large regions in the northeast and southeast Pacific. It was found that the largest, opposing terms on average were the entrainment velocity and vertical velocity.

The VAMOS Ocean-Cloud-Atmosphere-Land Study Regional Experiment (VOCALS-REx) was conducted off northern Chile and southern Peru and included airborne and shipborne meteorological and oceanographic observations during October/November 2008 (Wood et al., 2007). In this work we take advantage of the unprecedented wealth of data obtained during VOCALS-REx to characterize the MBL over the SEP. In the first part of our work (Rahn and Garreaud, 2009a) we documented the mean state (including its diurnal cycle) of the MBL. The different data sets acquired during VOCALS-REx were complemented with a 2-month long meteorological simulation using the Weather Research and Forecasting model (WRF, Skamarock et al., 2005). Both the observed datasets and setup of WRF are described in Rahn and Garreaud (2009a). Basically, we

Published by Copernicus Publications on behalf of the European Geosciences Union. 
employed meteorological upper-air data from radiosondes launched on the R/V Ron Brown and José Olaya, coastal sounding stations, and airborne measurements taken by the NSF C130 and DOE G1. The WRF simulation was initialized on 1 October 2008 and integrated continuously using GFS analyses as boundary conditions. The simulation has a grid spacing of $20 \mathrm{~km}$, covering a significant portion of the SEP and adjacent South America, and 44 sigma levels with telescoping resolution toward the surface.

In the present paper we focus on basic synoptic features and day-to-day changes of the MBL using the terms in the prognostic MBL depth equation. As in Part 1, observations and the WRF are used to depict the MBL variability and are compared to evaluate model performance. Documenting the day-to-day changes in the MBL structure also provides context to more detailed (e.g., aerosol measurements) studies during VOCALS-REx. Examination of the individual processes occurring within the MBL (i.e., generation of turbulent kinetic energy from cloud top radiative cooling, airsea transfer, decoupling, etc.) are largely ignored in favor of characterizing the terms of the prognostic MBL height equation that drive changes in the local MBL depth. Each term is fairly straightforward to calculate in a regional model except the entrainment velocity, which is calculated as the residual of the other terms in the equation. An understanding of the large scale variability of these terms provides a framework to diagnose phenomena on smaller scales and may be used to ensure that these variations are well-characterized and consistent with larger scale models such as global climate models.

In Sect. 2, the observed synoptic forcing and MBL variability during VOCALS-REx is presented to provide context for the subsequent analyses. Section 3 presents a diagnostic analysis of the MBL height, both for the mean state and the synoptic changes. The previous results help us to present in Sect. 4 a conceptual model of MBL variability over the SEP which is ultimately linked with midlatitude activity. Results are summarized in Sect. 5.

\section{Observed variability}

\subsection{Synoptic forcing}

Before discussing MBL variations over the SEP, NCEPNCAR reanalysis data is used to provide a large-scale perspective of the synoptic forcing during VOCALS-REx. Figure 1 shows the mean sea level pressure (SLP) and 500$\mathrm{hPa}$ geopotential height between 15 October and 29 November 2008, along with their anomalies with respect to the long-term mean (1979-2005). The subtropical high over the SEP was centered near its climatological position $\left(30^{\circ} \mathrm{S}\right.$, $100^{\circ} \mathrm{W}$ ) for austral spring. Well offshore and to the north of $45^{\circ} \mathrm{S}$ the SLP was higher than average by about $5 \mathrm{hPa}$, but anomalies in SLP decrease toward the coast such that
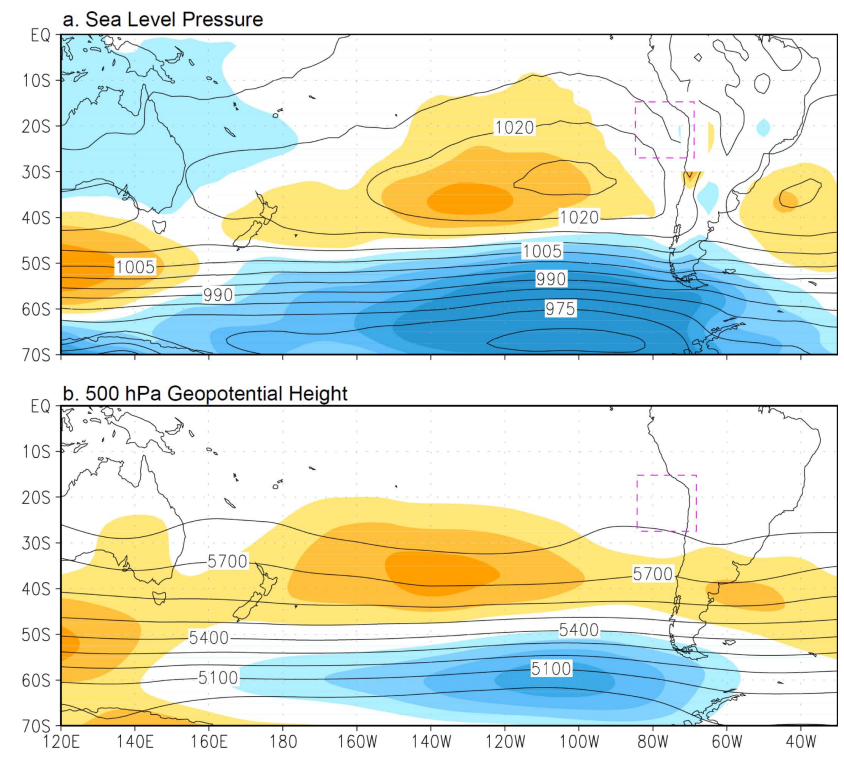

Fig. 1. NCEP-NCAR reanalysis of (a) mean sea level pressure ( $\mathrm{hPa}$, contours) and (b) mean 500-hPa geopotential height (m) from 15 October-29 November. Warm (cold) colors indicate positive (negative) departures from long-term mean $( \pm 3 \mathrm{hPa}$ for SLP and $\pm 50 \mathrm{~m}$ for Z500). Dashed box indicates VOCALS region.

in the VOCALS-REx region (defined as $17-25^{\circ} \mathrm{S}, 85^{\circ} \mathrm{W}$ to coast) they become negligible. Higher SLP is associated with stronger ridging aloft as seen in the 500-hPa geopotential height field. Weak troughing is present on average in the VOCALS-REx region. South of $45^{\circ} \mathrm{S}$ negative SLP anomalies are prevalent under negative height perturbations. This north-south dipole in SLP/height anomalies over the SEP leads to an increased gradient and thus stronger westerly winds around $45^{\circ} \mathrm{S}$. While such an enhanced storm track was primarily contained within the midlatitudes, there was some impact on the VOCALS-REx region.

Synoptic variability over the VOCALS-REx region is encapsulated by the time series of the 1000- and 500-hPa geopotential height and time-height diagrams of the tropospheric wind and vertical velocity from our WRF simulation (Fig. 2). During October 2008, the first part of VOCALS-REx, several disturbances sweep through the area. The 1000-hPa height alternates between periods of high and low height before leveling out after 26 October. Minimums in the 500-hPa geopotential height (troughs) are apparent around 3 October (T1), 14 October (T2), and 24 October (T3). These were not intense, but are associated with stronger westerlies aloft and intermittent, moderate northerly flow. Furthermore, while mid-tropospheric subsidence dominates on average, the vertical velocity exhibits significant variation over time (Fig. 2d). Rapid changes in the vertical motion occur with the passage of the troughs and exhibit strong dipoles of upward and downward motion during October. 

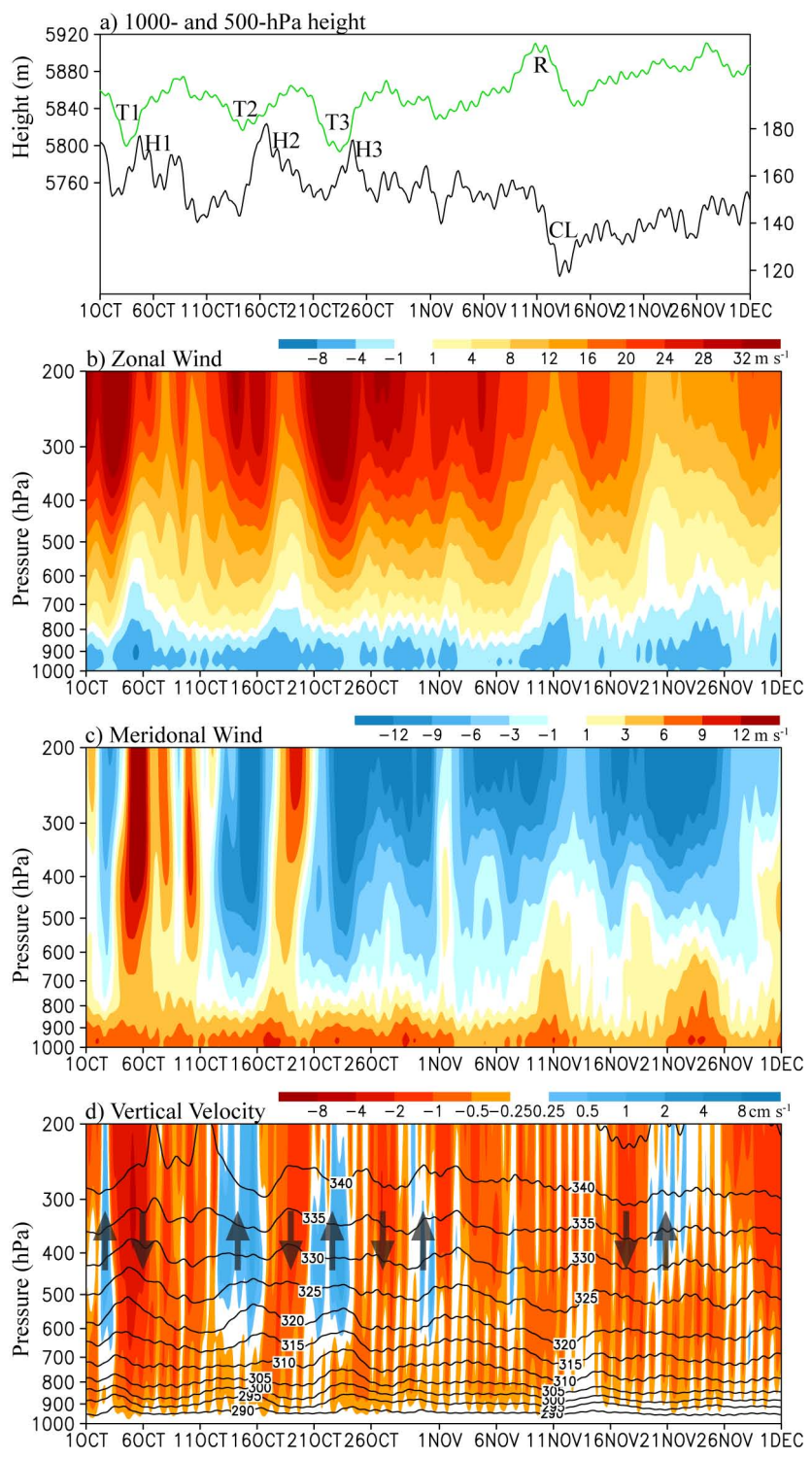

Fig. 2. (a) WRF-simulated evolution of the geopotential height (m) at $500 \mathrm{hPa}$ (green, scale on left) and $1000 \mathrm{hPa}$ (black, scale on right) averaged over the VOCALS region. Time-height diagrams of (b) zonal wind $\left(\mathrm{m} \mathrm{s}^{-1}\right)$, (c) meridional wind $\left(\mathrm{m} \mathrm{s}^{-1}\right)$, and (d) vertical velocity $\left(\mathrm{cm} \mathrm{s}^{-1}\right)$ averaged over the VOCALS region. Arrows and labels indicate significant events described in text.

The second half of VOCALS-REx (November 2008) featured less disturbed conditions. After 1 November the 500$\mathrm{hPa}$ height increases over the area through 11 November. Height increase is associated with ridging $(\mathrm{R})$ which drives a warming of the lower and middle troposphere and leads to the formation of a coastal low (CL) as seen in the sharp decrease of the average 1000-hPa height (Garreaud et al., 2002; Garreaud and Rutllant, 2003). Ridging gives way to a cutoff low that reaches a minimum on 15 November. In the beginning of November there is persistent subsidence associated

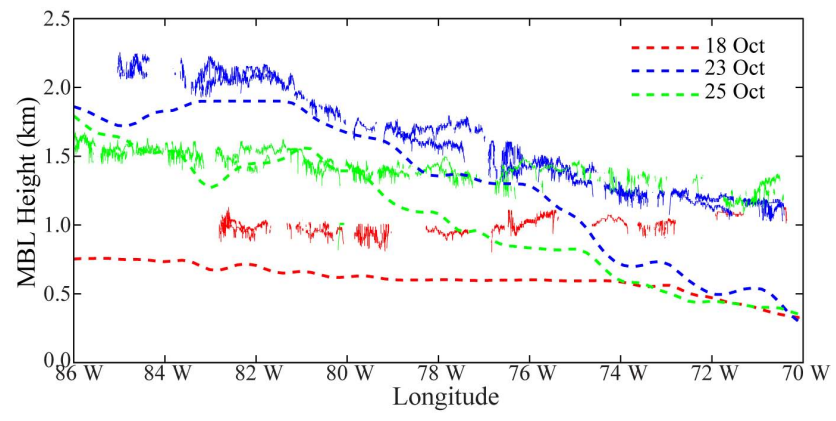

Fig. 3. Examples of the MBL depth along $20^{\circ} \mathrm{S}$ from the WRF (dashed) and detected by the Wyoming Cloud Radar (solid) for 18 October (red), 23 October (blue), and 25 October (green).

with the ridging and development of the CL. An exception is when there is weak vertical motion at low levels (under $700 \mathrm{hPa}$ ) between 12 and 15 November, which is associated with the meridional convergence downstream of a coastal jet that often forms off of central Chile (Garreaud and Muñoz, 2005).

\subsection{MBL changes}

The evolving synoptic environment resulted in sizeable changes in the lower-troposphere structure, which were well sampled by the many $\mathrm{C} 130$ research flights in transects along $20^{\circ} \mathrm{S}$ from the coast to about $85^{\circ} \mathrm{W}$ (Rahn and Garreaud, 2009a). In particular, the MBL depth was derived from cloud top height as detected by the Wyoming Cloud Radar onboard the C130. Figure 3 shows examples of the observed MBL depth profile for three days around the passage of the third trough (T3) and features deep, shallow, and average conditions. Large variations are observed to the west of $75^{\circ} \mathrm{W}$ with MBL depth ranging from $1000 \mathrm{~m}$ to $2200 \mathrm{~m}$ at $85^{\circ} \mathrm{W}$. In contrast, MBL depth remains remarkably steady around $1200 \mathrm{~m}$ in the near shore strip. For comparison, we have included the WRF-simulated MBL depth for each case in Fig. 3. As seen in Part 1, the largest discrepancy is near the coast where the MBL is $\sim 500 \mathrm{~m}$ shallower in the simulation. Offshore, the model does capture the MBL depth variations fairly well during these three distinct periods.

To further characterize the MBL variations during VOCALS-REx we have compiled all available observations at $20^{\circ} \mathrm{S}, 80^{\circ} \mathrm{W}$, hereafter Point Omega. Figure $4 \mathrm{a}$ depicts a time series of the MBL depth from the $\mathrm{C} 130$ and $\mathrm{R} / \mathrm{V}$ Ron Brown measurements (filled circles) and those derived from MODIS data (open triangles) using the algorithm developed in Zuidema et al. (2009). There is good agreement between in-situ and remotely-sensed MBL depths during the whole period. Figure $4 \mathrm{a}$ also includes the WRF simulated MBL depth at Point Omega. In October, the observed and simulated MBL depths have comparable variations, but the 

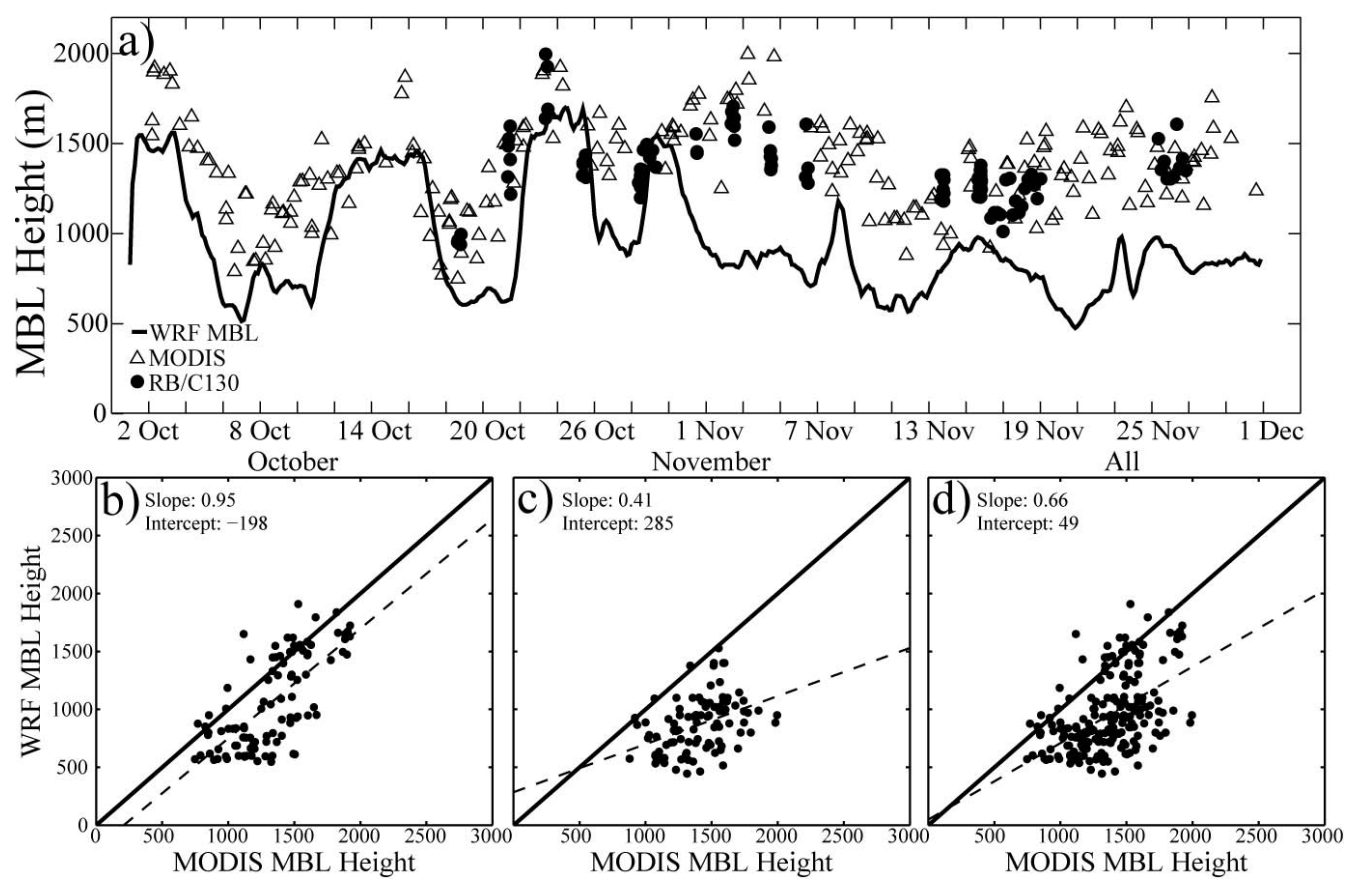

Fig. 4. (a) Time series of MBL height (m) from the C130 and Ron Brown (circle), MODIS (triangle), and WRF (black line) at Point Omega $\left(20^{\circ} \mathrm{S}, 80^{\circ} \mathrm{W}\right)$. Comparison of MODIS and WRF MBL depth $(\mathrm{m})$ for $(\mathbf{b})$ October, (c) November, and (d) the entire two months. The one-to-one line is the bold line and the linear fit is the dashed line.

simulated MBL is typically $200 \mathrm{~m}$ lower than those observed, also evident in the scatter plot shown in Fig. 4b. Because the variation is the primary interest in this study, a simple underestimate of the MBL depth does not impact the results as much as a random or incoherent variation. In contrast to October, during November (Fig. 4c) there is less correlation between observations and simulations, and the simulated MBL is consistently lower than the observed MBL. This is attributed to the lack of strong synoptic changes that are able to modify the MBL height so that the noise obscures any trend.

The observations, complemented with the WRF results, suggest a bimodal distribution of the MBL depth at Point Omega during October with instantaneous values clustered around a low $(\sim 600 \mathrm{~m}$ a.s.l.) or high $(\sim 1500 \mathrm{~m}$ a.s.l. $)$ depth. During October, the MBL depth remained low or high for several days, interrupted by rapid (12-36h) transitions between these two states. In November, the MBL mostly remained low without the cyclical transitions. The much more variable conditions during October are consistent with the more active synoptic forcing during the first half of VOCALS-REx.

\section{MBL diagnostics}

In Part 1 of this work we documented the mean state of the lower troposphere over the SEP and compared observations with WRF results. Definition of the MBL height is described in Sect. 2.2 of Part 1. Here we perform a diagnostic analysis of the MBL largely on the basis of the WRF simulation. Change of local MBL depth $(H)$ over time is given by the following relationship (Schubert et al., 1979):

$$
\frac{\delta H}{\delta t}=-V \cdot \nabla H+w_{\mathrm{LS}}+w_{\mathrm{E}}
$$

where $-V \cdot \nabla H$ is the horizontal advection of the MBL height by the wind at the top of the MBL, $w_{\mathrm{LS}}$ is the large scale vertical velocity at MBL top, and $w_{\mathrm{E}}$ is the entrainment velocity. There are several issues in calculating this from model output. Since output was every three hours over the two month run, the change of MBL depth over time is not the instantaneous change, but is the three hour change of MBL depth. Advection was calculated after applying a spatial nine-point smoother (weights of $1,0.5$, and 0.3 to the center, sides, and corner points) over both MBL depth and also wind. This reduced some of the noise that comes from working with finite data. For example vertical resolution was about $50 \mathrm{~m}$ at the average MBL depth so this relaxes the discrete jumps in the gradient. Large scale vertical velocity was obtained from the grid point above the inversion base and a nine-point smoother was also applied. This reduces the 
noise and also allows the other points to exert some influence. Since the previous terms can be calculated explicitly from WRF output, these three terms were used to calculate an approximate $w_{\mathrm{E}}$. Because there are errors associated with all the calculations (e.g., instantaneous change of height is calculated over three hours, the smoothed $w_{\text {LS }}$ may not be entirely representative of the larger scale subsidence, wind velocity in the advective term is somewhat sensitive to large wind shear near the inversion, etc.) this term does contain more than just the entrainment velocity and so it is referred to as the residual term instead of just the entrainment velocity to acknowledge these issues. The diurnal cycle is not filtered out since synoptic variation dominates.

Another possible source of error in the model is the enhanced gradient (as compared to observations) in MBL height near the shore $\left(75-70^{\circ} \mathrm{W}\right)$ that enhances advection. Given an east-west bias as great as $500 \mathrm{~m} / 500 \mathrm{~km}$ (Fig. 3) and cross-gradient winds from $1-5 \mathrm{~m} \mathrm{~s}^{-1}$, there can be biases up to $1-5 \mathrm{~mm} \mathrm{~s}^{-1}$ in the advection. As will be seen later on, these changes can be small compared when there is a large signal driven by synoptic forcing (on the order of $1-3 \mathrm{~cm} \mathrm{~s}^{-1}$ for the more extreme cases). Since the major biases are in the near coast region, focus is on points farther offshore to help diffuse the impact of these biases on the conclusions drawn from WRF.

\subsection{Mean state}

Figure 5 shows the model-derived October and November 2008 mean of the SLP and 10-m wind as well as the MBL depth and wind at the top of the MBL. The figure also shows the standard deviation of SLP and MBL depth. Consistent with the reanalysis, the simulated SLP and 10-m wind fields exhibits an anticyclone centered near its climatological position at $30^{\circ} \mathrm{S}, 95^{\circ} \mathrm{W}$. SLP variability gradually increases southward, from about $2 \mathrm{hPa}$ in the subtropics to more than $5 \mathrm{hPa}$ at $45^{\circ} \mathrm{S}$ signaling the midlatitude storm track. South of $20^{\circ} \mathrm{S}$, the standard deviation of SLP also exhibits a gentle decrease toward the coast, consistent with a tendency for the weather systems to decay as they approach western South America (e.g., Barrett et al., 2009).

As noted in Part 1, average MBL depth increases offshore and the basic structure is similar, albeit offset lower, to a September-October 2000 average (Wood and Bretherton, 2004), a July 2006-June 2007 average (Leon et al., 2008), and an October 2008 average (Zuidema et al., 2009). The deepest MBL $(\sim 1600 \mathrm{~m})$ occurs at $20^{\circ} \mathrm{S}, 100^{\circ} \mathrm{W}$. MBL height is very low near the continent and the contours parallel the coastline, an aspect that is consistent with the alongshore observations in Rahn and Garreaud (2009a). The MBL depth standard deviation field resembles its SLP counterpart with a general increase southward, reflecting the passage of midlatitude weather systems. There are, however, important differences. Near the coast and south of $25^{\circ} \mathrm{S}$, the variation of MBL depth increases toward the coast while the variation
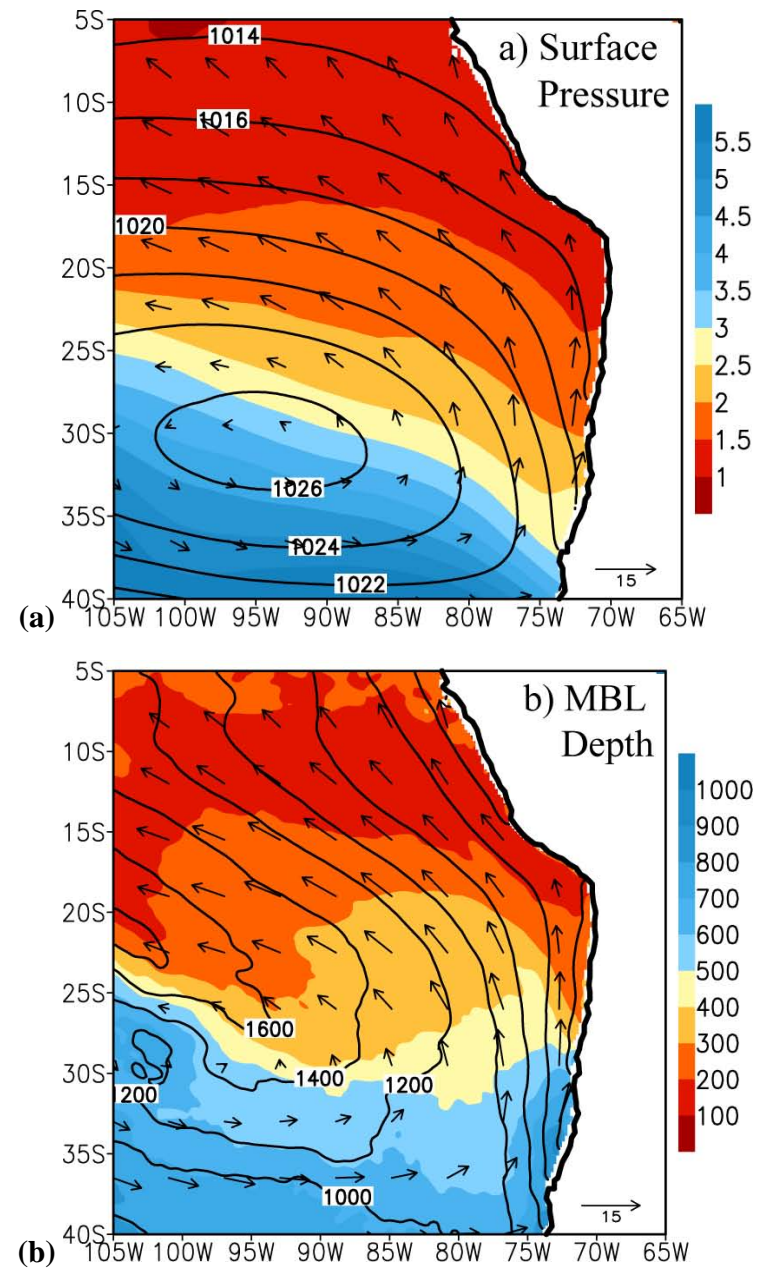

Fig. 5. (a) WRF-derived mean sea level pressure (hPa, contours), standard deviation of sea level pressure (hPa, color), and mean 10$\mathrm{m}$ wind ( $\mathrm{m} \mathrm{s}^{-1}$, vectors). (b) WRF-derived mean MBL height ( $\mathrm{m}$, contours), standard deviation of MBL height (m, color), and mean wind at top of MBL (vectors, $\mathrm{m} \mathrm{s}^{-1}$ ) during October and November 2008 .

of surface pressure decreases toward the coast. This is in the region of land falling systems and the common occurrence of the coastal jet. Terrain blocking of low-level westerly wind can greatly deepen the MBL while strong southerly coastal jets are associated with a thin MBL (Garreaud and Muñoz, 2005). The coastal observations in Part 1 indeed showed that the MBL at Santo Domingo $\left(33^{\circ} \mathrm{S}\right)$ was much more variable than at Paposo $\left(25^{\circ} \mathrm{S}\right)$. The relatively high variability of the MBL off central Chile appears to be advected by the wind at the top of the MBL creating a swath of relatively higher variability that extends into the open ocean and influences subtropical latitudes. This is an interesting feature, not present in the SLP standard deviation field, which indicates the influence of the midlatitudes extending to the subtropics. 

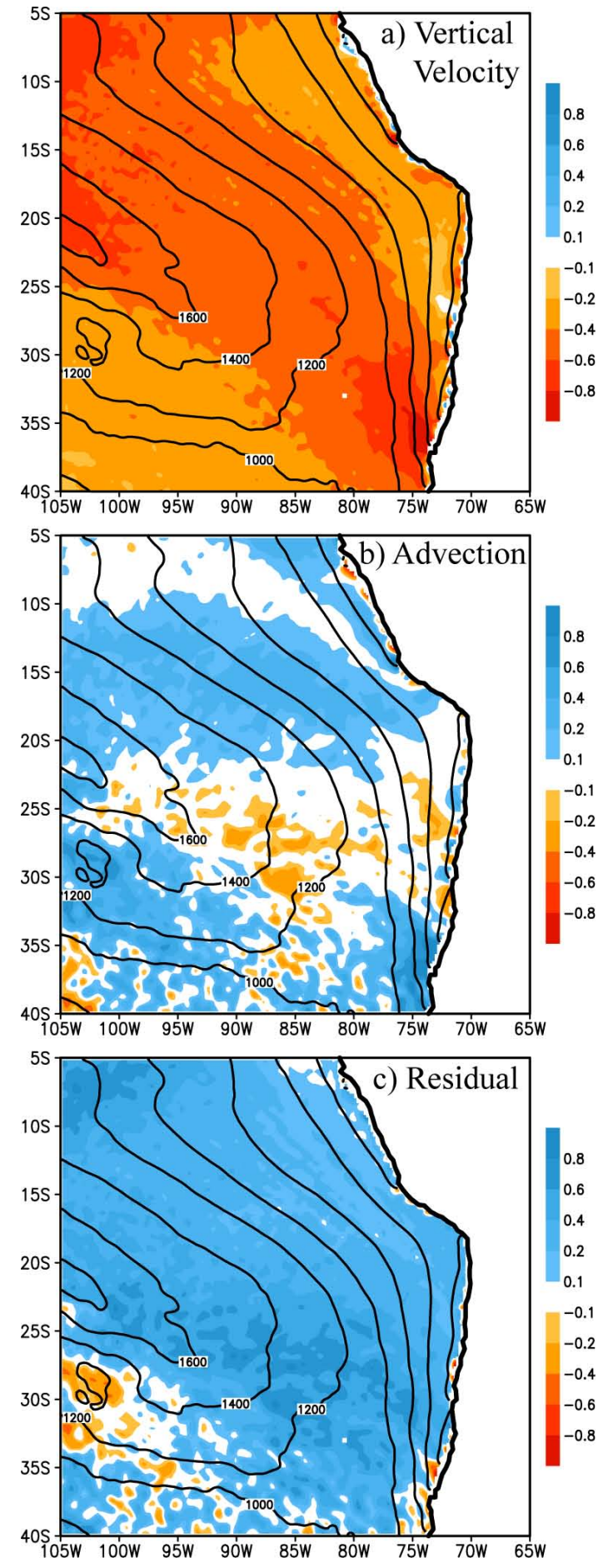

Fig. 6. October and November mean of (a) vertical velocity, (b) advection, and (c) residual $\left(10^{-2} \mathrm{~m} \mathrm{~s}^{-1}\right.$, color). Mean MBL height (m) shown by contours. All fields from the WRF simulation.

Averages of the individual terms of Eq. (1) over the twomonth simulation are presented in Fig. 6. Vertical velocity at the top of the MBL ranges between -2 and $-6 \mathrm{~mm} \mathrm{~s}^{-1}$ over most of the domain with the higher values contained in
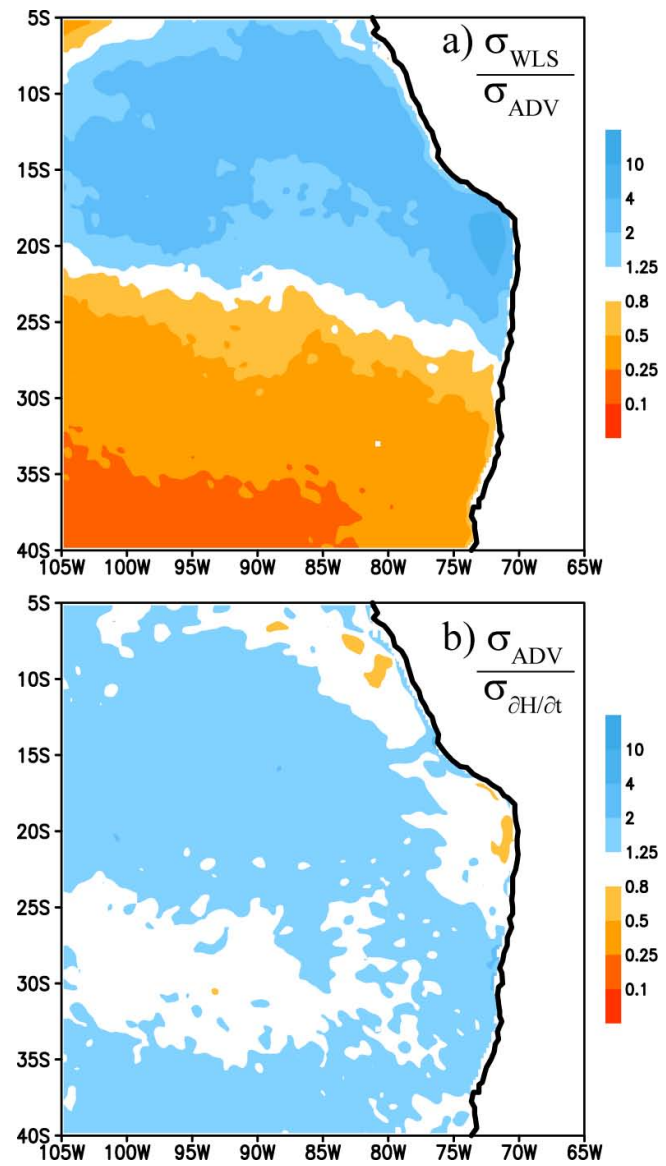

Fig. 7. Ratios of standard deviations of (a) large scale subsidence to advection and (b) advection to $\partial H / \partial t$. All fields from the WRF simulation.

a broad swath extending from the northwest to the southeast (Fig. 6a). Enhanced (diminished) subsidence is near the coast south (north) of $30^{\circ} \mathrm{S}$ and is linked to the entrance (exit) region of a coastal jet (Muñoz and Garreaud, 2005). Average advection is generally smaller in magnitude $\left(<2 \mathrm{~mm} \mathrm{~s}^{-1}\right)$ and may be either negative or positive (Fig. 6b). An area of positive advection extends along $15^{\circ} \mathrm{S}$. The average residual is by and large positive with a notable exception in the far southwest region of the domain (Fig. 6c) where the MBL is defined less of the time. Values of the residual are slightly greater in the same general northwest to southeast swath as the vertical velocity, suggesting the dominance of the two terms in the mass balance in agreement with previous studies (Wood and Bretherton, 2004).

\subsection{Variability}

To begin assessing the MBL variability, the standard deviation of each term in Eq. (1) during the two month period is calculated. Because it is the relative importance between the terms that is of primary interest, these can be expressed in terms of their ratios. An important comparison is between 

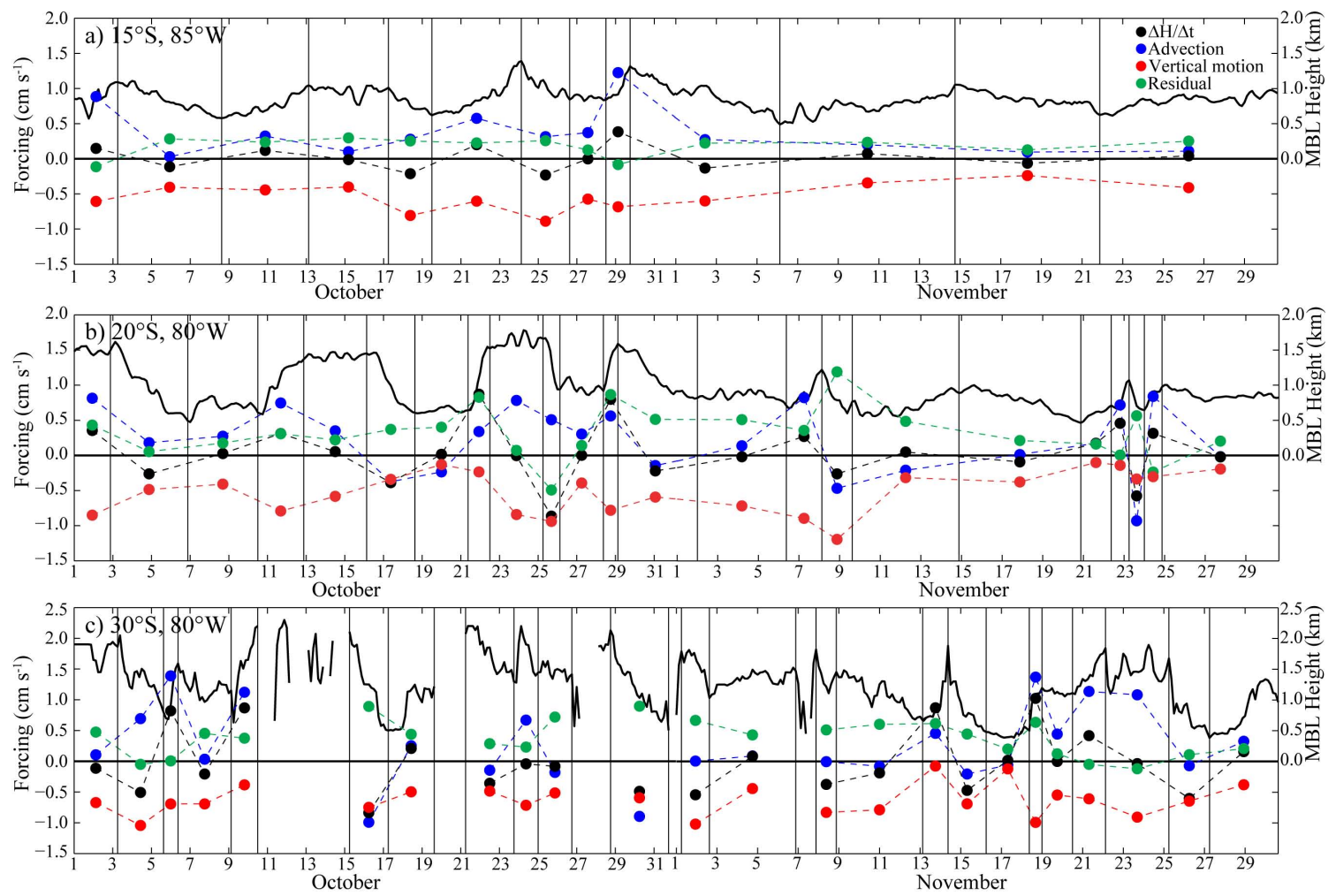

Fig. 8. Time series of WRF-simulated MBL height ( $\mathrm{m}$, solid contour), and averages of three-hour change of height ( $\mathrm{cm} \mathrm{s}^{-1}$, black), advection $\left(\mathrm{cm} \mathrm{s}^{-1}\right.$, blue), vertical motion at MBL top $\left(\mathrm{cm} \mathrm{s}^{-1}\right.$, red), and residual ( $\mathrm{cm} \mathrm{s}^{-1}$, green). Time range of averages indicated by vertical lines. Locations are at (a) $15^{\circ} \mathrm{S}, 85^{\circ} \mathrm{W}$, (b) $20^{\circ} \mathrm{S}, 80^{\circ} \mathrm{W}$, and (c) $30^{\circ} \mathrm{S}, 80^{\circ} \mathrm{W}$.

the variation of the vertical velocity and advection (Fig. 7a). North of $20^{\circ} \mathrm{S}$ and within the Peruvian Bight, the standard deviation of vertical velocity is almost twice as large as the standard deviation of advection. South of $25^{\circ} \mathrm{S}$, the reverse is true with the standard deviation of advection being about twice as large as the standard deviation of vertical velocity. Between $20-25^{\circ} \mathrm{S}$ the variation of the two terms are similar. The ratio of the advective term to the local change of MBL depth term suggests a correlation in the variability between these two terms since throughout the domain they are close (Fig. 7b). The ratio is $1.25-2$ for nearly the entire domain and $0.8-1.25$ for the other regions. Thus, the advection shows slightly more variability than the local change of MBL depth suggesting that forcing by the advective term is most likely damped or compensated by the other terms. Even with more variation in the vertical velocity towards the equator relative to the advection, the actual variation in the MBL depth is smaller and on the same order as the advection.

To illustrate the relative importance of the individual terms in the MBL height equation, several time series have been prepared (Fig. 8). Locations are selected deep into the SEP at $15^{\circ} \mathrm{S}, 85^{\circ} \mathrm{W}$, in the midst of VOCALS-REx measurements at Point Omega, and approaching the midlatitudes at $30^{\circ} \mathrm{S}$, $80^{\circ} \mathrm{W}$. Terms are averaged over periods that have an MBL with rising height, constant height, or lowering height. Ave- rages of each period (identified by vertical lines) are shown as color-coded points in the center of each region. At $15^{\circ} \mathrm{S}$, $85^{\circ} \mathrm{W}$ the MBL depth ranges from $600-1400 \mathrm{~m}$ and there are gradual changes in MBL depth that persist over periods of 4 7 days. Subsidence is balanced nearly equally by the residual and advection. While the residual remains fairly constant around $2.5 \mathrm{~mm} \mathrm{~s}^{-1}$, the advection exhibits a larger range $(0$ $10 \mathrm{~mm} \mathrm{~s}^{-1}$ ).

In the VOCALS-REx region at Point Omega, variation of the MBL increases and the range extends over $500-1700 \mathrm{~m}$. Vertical velocity varies between about -3 to $-5 \mathrm{~mm} \mathrm{~s}^{-1}$. The residual is always positive with one exception during a short time period of rapid MBL decrease and has an average of $3.0 \mathrm{~mm} \mathrm{~s}^{-1}$. Advection is variable and has an average of $1.7 \mathrm{~mm} \mathrm{~s}^{-1}$. Throughout most of November the largest opposing terms are the vertical velocity and residual. This represents the more tranquil environment and slower changes in the boundary layer in contrast to the previous month where the area was influenced heavily by synoptic disturbances.

Toward the midlatitudes the MBL and forcing terms exhibit much greater variability than their counterparts to the north. Because these are more strongly influenced by midlatitude disturbances, the inversion at the top of the MBL may be totally eroded with the passage of a particularly strong event, leaving gaps in the time series. These are excluded 

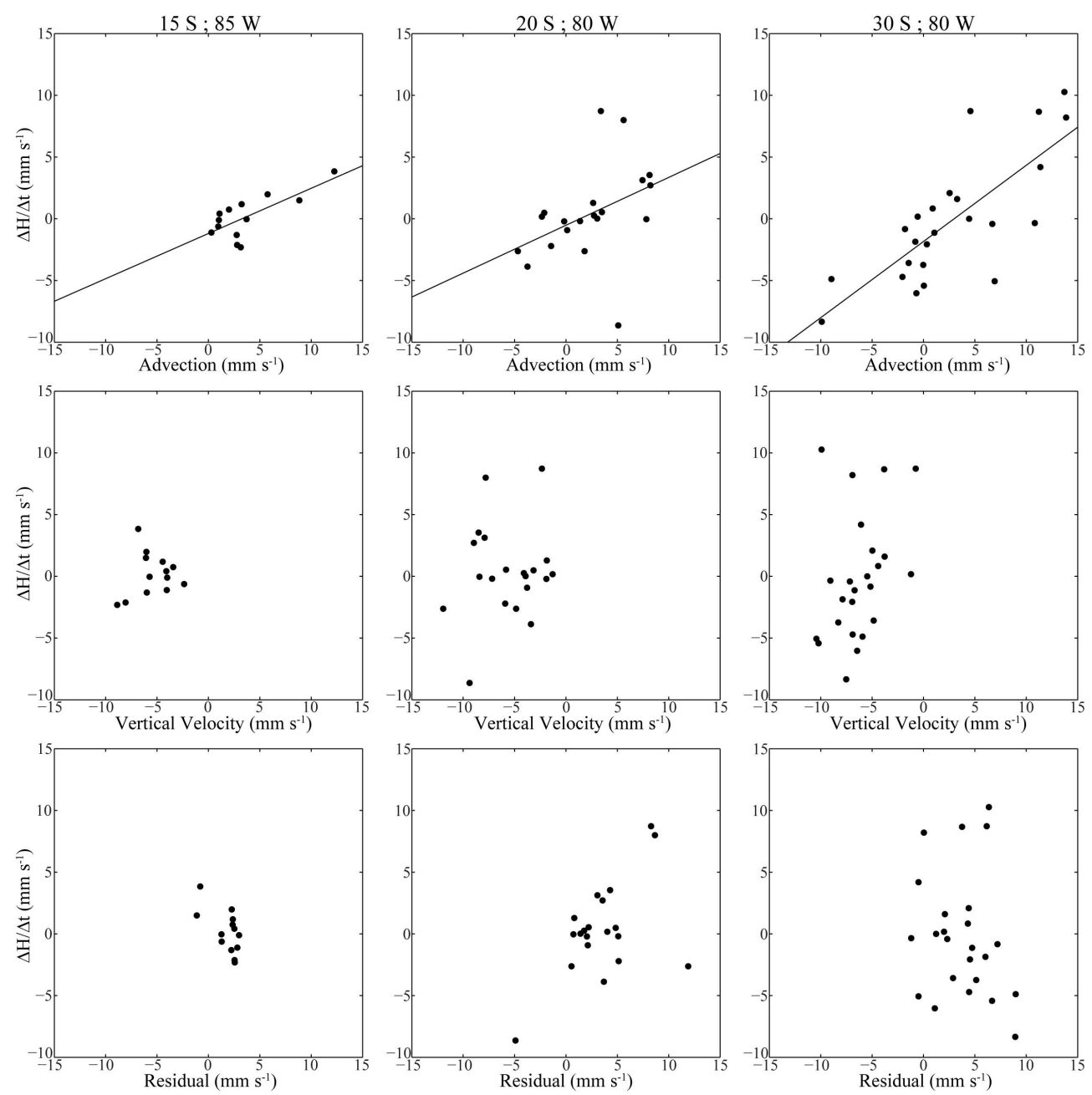

Fig. 9. Relation between changes in depth and the advective (top), vertical velocity (center) and residual (bottom) terms. Locations are $15^{\circ} \mathrm{S}$, $85^{\circ} \mathrm{W}$ (left), $20^{\circ} \mathrm{S}, 80^{\circ} \mathrm{W}$ (center), and $30^{\circ} \mathrm{S}, 80^{\circ} \mathrm{W}$ (right). Lines on top are from a standard linear regression. Each dot represents the average value in the time period indicated in Fig. 8.

from the analysis. However, the conclusions are consistent. The vertical velocity at the top of the MBL and the residual are generally large and opposing while the advection is much more variable and related to the changes in the MBL depth with time.

Of all the terms, the advection and the change of MBL depth over time seem to be better related, as illustrated in the scatter plots in Fig. 9. At Point Omega, there is a linear correlation between advection and MBL height except for three short (less than one day) periods of rapid MBL change that led to outliers. The slope of the linear fit is $\sim 0.4$ indicative that the horizontal advection effect on MBL depth is somewhat damped by the other terms. Additionally, this slope is consistent with the ratio between the standard deviation of the advection to the standard deviation of the rate of change of MBL depth (0.5) shown in Fig. 7b near Point Omega. The slope in the south is greater $(\sim 0.6)$ so that the two are more directly related. Standard deviation of the two should be closer, and this is true since the ratio between the two is closer to one (Fig. 7b). Comparison with the vertical velocity and residual is shown in the middle and lower rows, but do not yield a clear relationship.

\subsection{Case studies}

Three events illustrate the instantaneous spatial distributions of the individual terms that contribute to increasing, no change, or decreasing MBL depth at Point Omega. Deepening of the MBL near Point Omega takes place at 06:00 UTC 10 October (Fig. 10). Wind at the top of the MBL is clearly moving across the MBL height contours toward lower MBL height in the region south of $20^{\circ} \mathrm{S}$ and west of $75^{\circ} \mathrm{W}$, which is also the area of the largest MBL change. Contours of the advective term coincide well with those of MBL change over time. Vertical velocity shows less correlation with the increase of MBL depth, but there is some upward motion just 


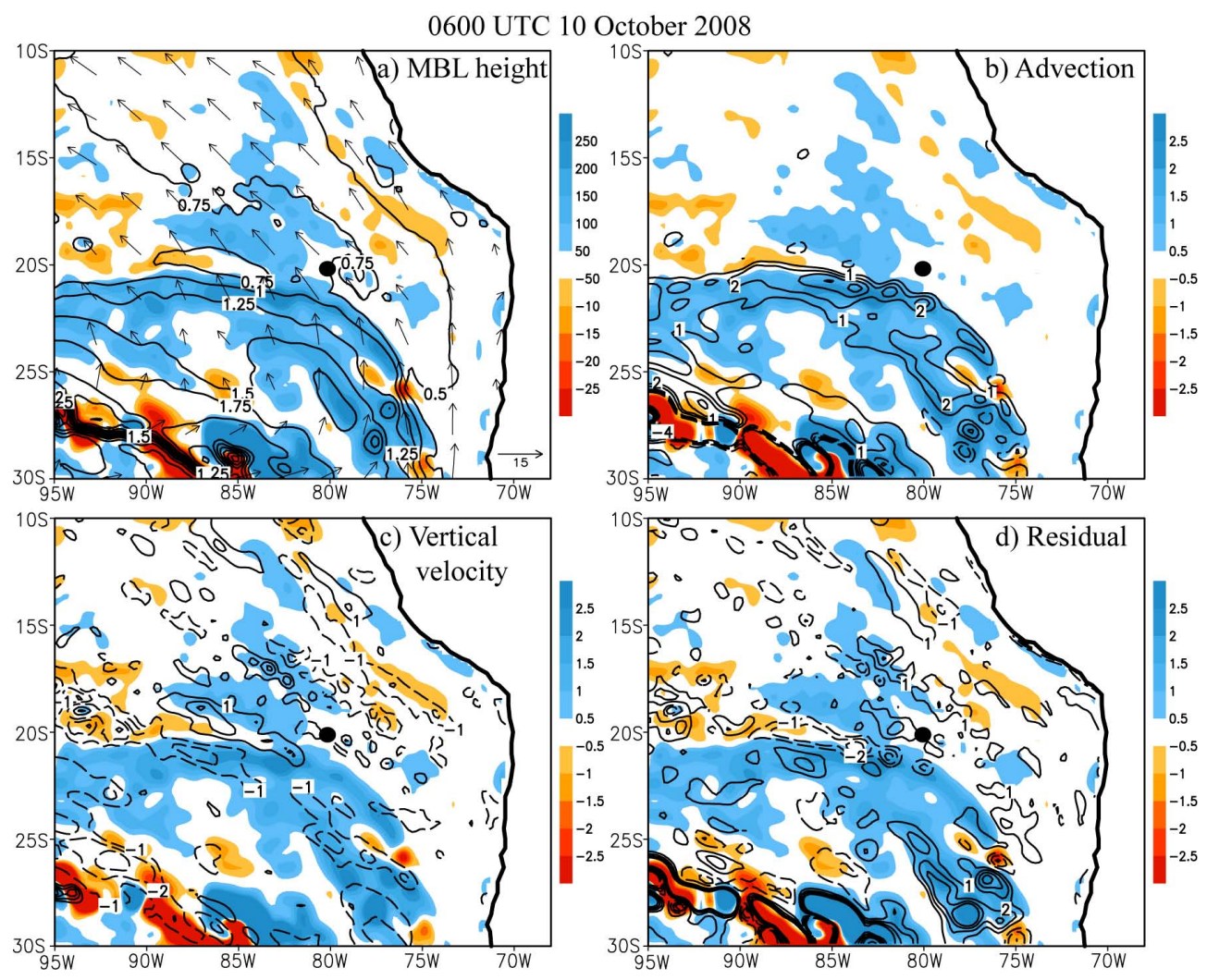

Fig. 10. On 06:00 UTC 10 October (a) WRF-simulated MBL depth (km, contours) and three-hour change of MBL depth (m, color), (b) advection $\left(\mathrm{cm} \mathrm{s}^{-1}\right.$, contour) and $\partial H / \partial t\left(\mathrm{~cm} \mathrm{~s}^{-1}\right.$, color), (c) vertical velocity $\left(\mathrm{cm} \mathrm{s}^{-1}\right)$ and $\partial H / \partial t\left(\mathrm{~cm} \mathrm{~s}^{-1}\right.$, color), and (d) residual (cm s${ }^{-1}$, contour) and $\partial H / \partial t\left(\mathrm{~cm} \mathrm{~s}^{-1}\right.$, color).

north of the largest MBL increase around $18^{\circ} \mathrm{S}, 85^{\circ} \mathrm{W}$ that is contributing to the deepening of the MBL. Off the Peruvian coast there is a band of downward motion along a northwest axis associated with lower depths, presumably associated with the upsidence wave that is generated diurnally near the continent (Garreaud and Muñoz, 2004). The residual is generally positive and does not have any large features such as the advective term or vertical velocity with the exception of high values in the far south and west due to a developing MBL.

On 21:00 UTC 15 October the MBL depth is fairly stable around Point Omega (Fig. 11) and the terms themselves are fairly weak and diffuse. Elsewhere, advection does show some correlation again with changes in MBL depth. Vertical velocity correlates well with the lowering of MBL depth in regions in the southwest portion of the domain while residual values act to deepen the MBL over the entire area without much preference in location. The two terms that tend to dominate the balance at Point Omega and elsewhere in the domain during this time are the vertical velocity and residual, resembling the mean-state balance discussed before (Fig. 5).

During the next period at 21:00 UTC 17 October, the MBL depth is rapidly decreasing near Point Omega (Fig. 12). Offshore flow increased and was sustained over the previous day.
Contours of the MBL continue to be primarily meridional, setting up a sizeable along-gradient wind component so that the advective term once again dominates these large changes in the MBL depth. Enhanced subsidence to the northwest of the area of rapid MBL depth decrease aids in the thinning of the MBL, but it is clearly smaller than the advective term. The residual term is large in the region of maximum MBL decrease. Otherwise the distribution is relatively diffuse and weakly positive.

\section{A conceptual model of the synoptic forcing}

Large, synoptically-driven MBL depth variations at subtropical latitudes (e.g., at Point Omega) are primarily driven by horizontal advection, while vertical velocity and entrainment tend to damp those changes and dominate during more stable conditions. Granted, the advection of lower or higher heights only represents a translation of MBL depth from one location to another and it is not a basic mechanism that changes the MBL depth in a Lagrangian sense. Changes in horizontal advection affecting the MBL over the subtropical SEP are in turn associated with changes in the wind field and the MBL farther south connected with the passage of midlatitude 


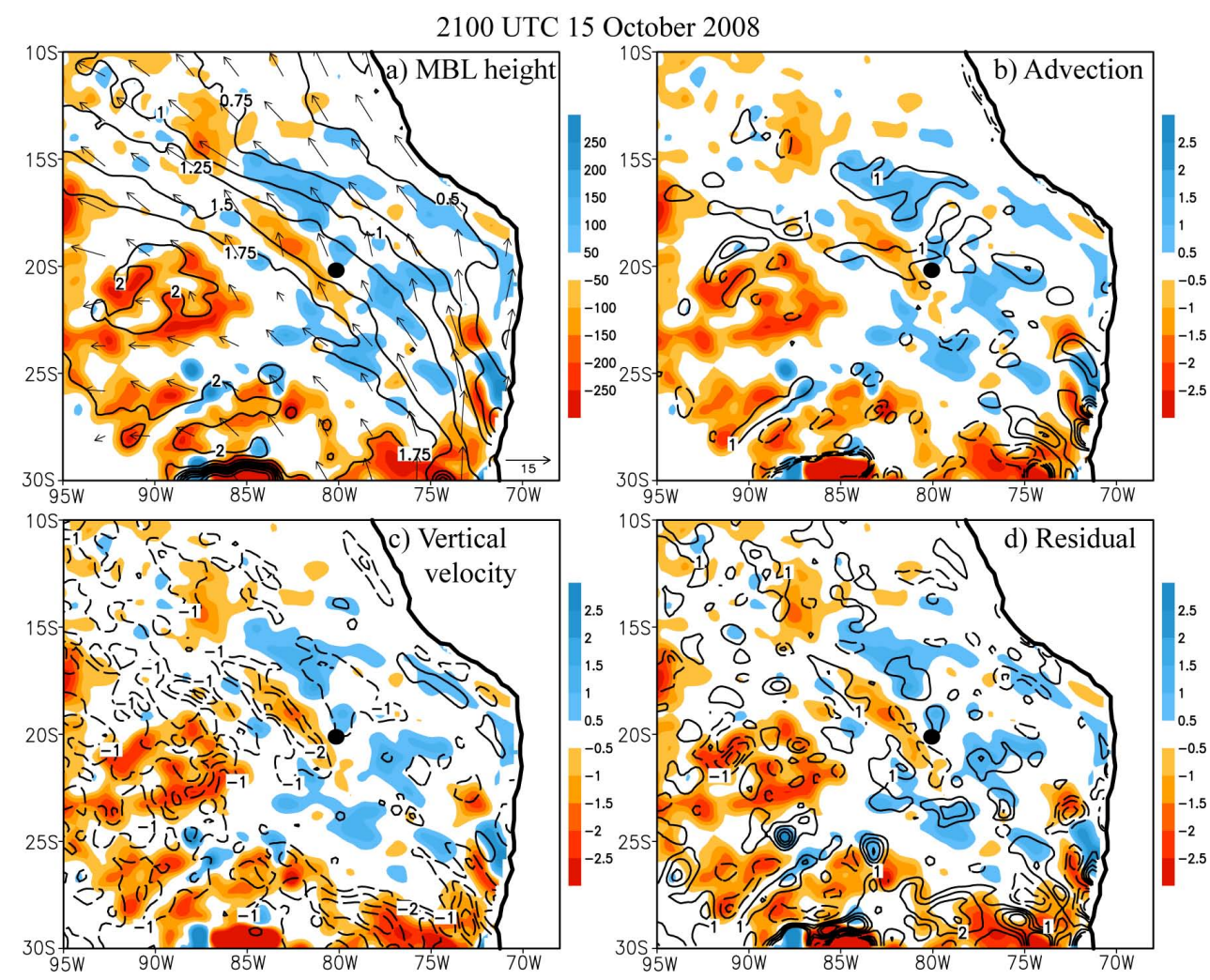

Fig. 11. As Fig. 10, but for 21:00 UTC 15 October.

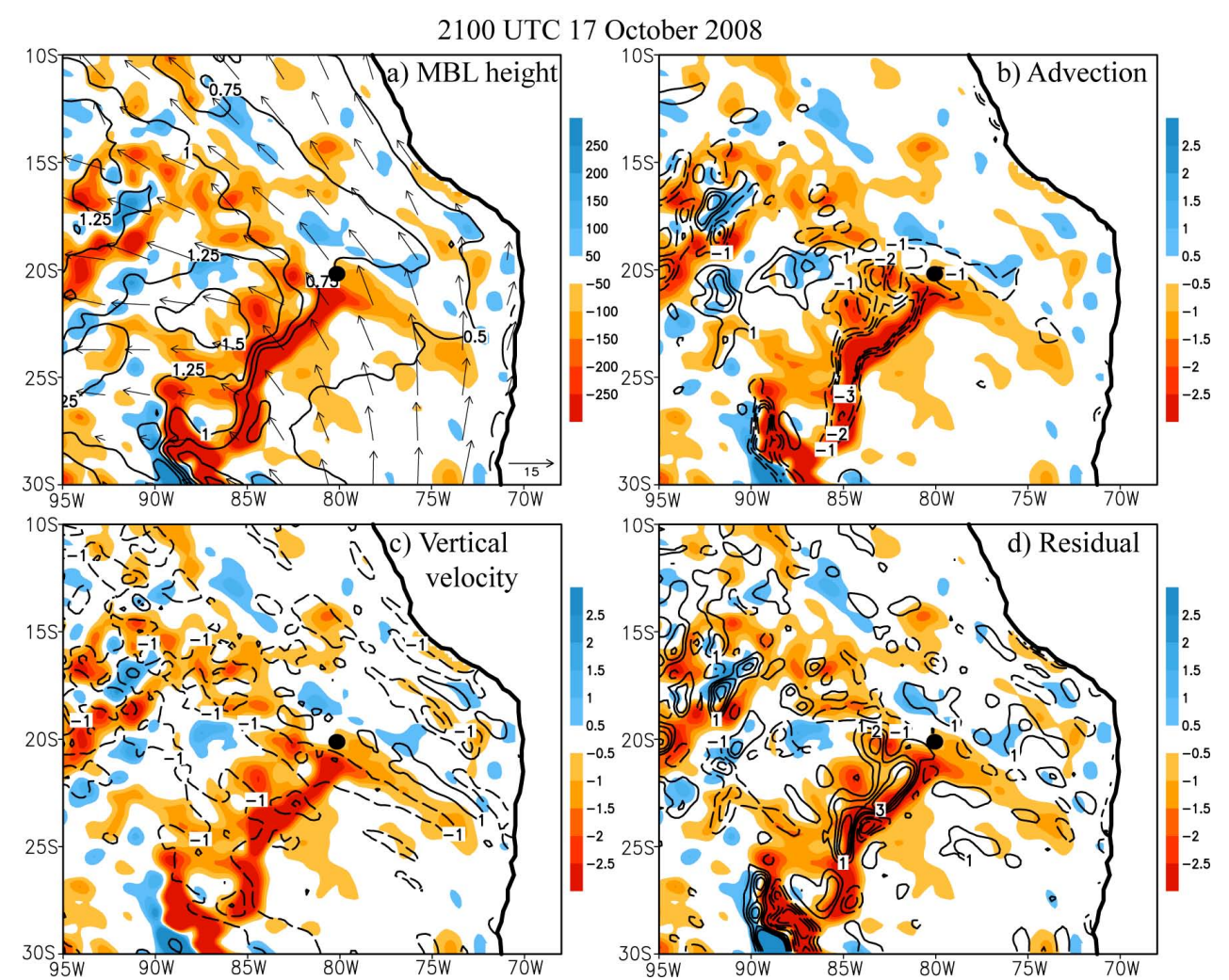

Fig. 12. As Fig. 10, but for 21:00 UTC 17 October. 

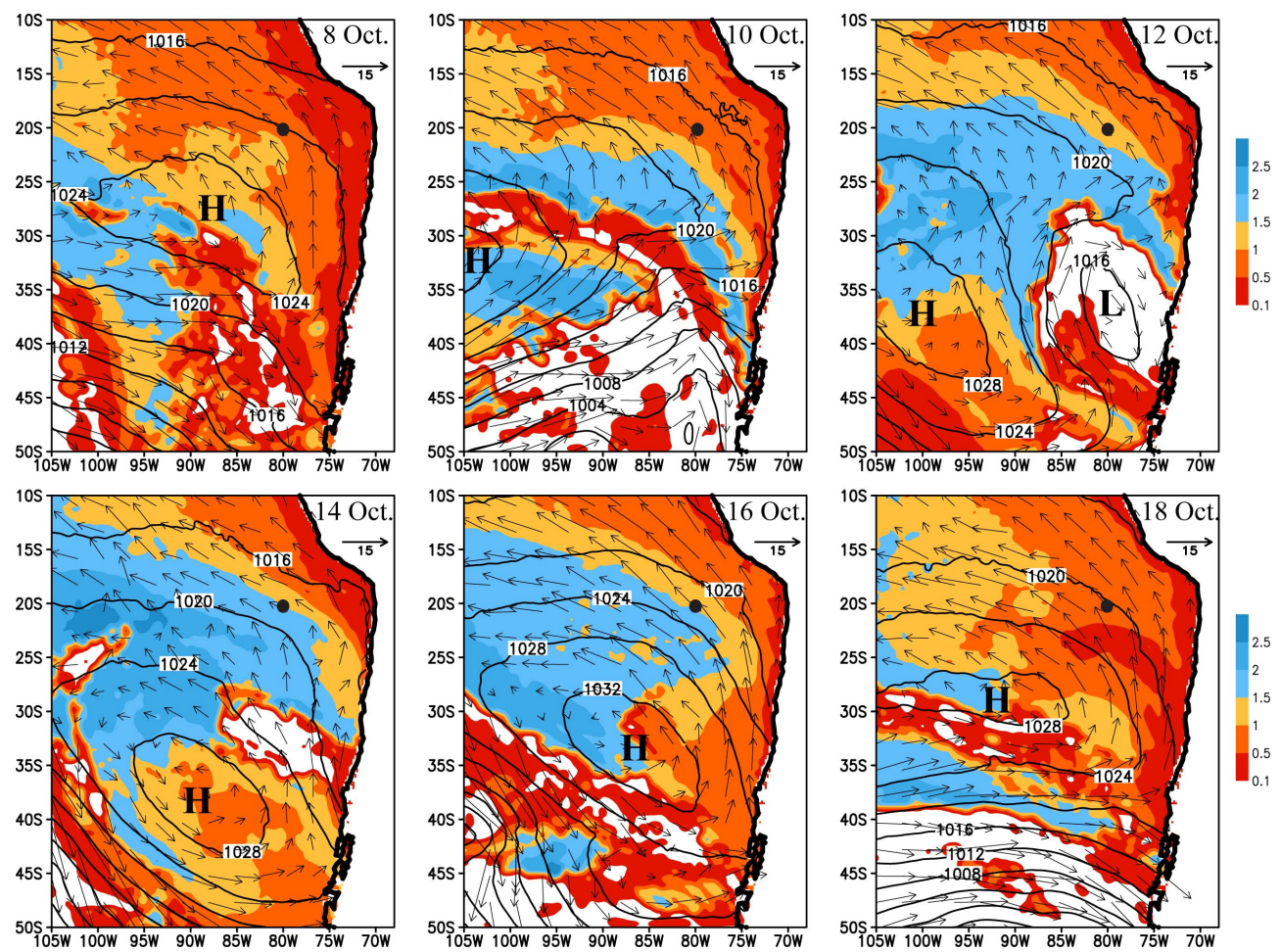

Fig. 13. WRF-simulated sea level pressure (contours, hPa), MBL height (color, $\mathrm{km}$ ), and wind $\left(\mathrm{m} \mathrm{s}^{-1}\right.$ ) at 12;00 UTC for several days (dates indicated in each panel). Wind is at the MBL top when MBL is defined and at the surface when not defined.

waves. Keeping in mind that we try to interpret changes near Point Omega, a full cycle of a cyclone passage (8-18 October 2008) is depicted by the surface pressure, wind at the top of the MBL, and MBL height in Fig. 13. During the passage of strong events of upward motion, the inversion defining the MBL erodes and thus the MBL height is undefined. At times a shallow mixed layer forms near the surface when the MBL is eroded in this manner. This creates some apparent discontinuities in the field, but the basic structure should still be readily discernible. When the MBL is undefined, the wind is taken to be at $10 \mathrm{~m}$ simply for continuity.

On 8 October there is a shallow MBL near Point Omega, the high pressure is centered northeast of its climatological position, and a region of low pressure is moving into the southwest corner of the domain. Two days later the cyclone is just west of southern Chile and a cold front (inferred from the local minimum in SLP) arches equatorward. The MBL is ill-defined along the front, but over the post-frontal anticyclone the MBL is deep. On $12^{\prime}$ October there is a dramatic change in the low-level wind over the southeast Pacific that blows from the SSW south of $25^{\circ} \mathrm{S}$, advecting the deep postfrontal MBL into subtropical latitudes. By 14 October the anticyclone again dominates the entire SEP and a deep MBL prevails over much of the region. As the anticyclone moves closer to the coast on 16 October, there is an enhanced northsouth pressure gradient along the coast leading to a stronger offshore wind that crosses from lower to higher MBL height.
By 18 October the advection of the lower heights originating near the shore now extends over most of the region depressing the MBL as far west as Point Omega.

While there is certainly variability in synoptic situations, there appears to be some fundamental characteristics of a midlatitude cyclone passage that influences the MBL height into the subtropics. Figure 14 illustrates the conceptual model of the SEP during times of stable, decreasing, and increasing MBL height. Periods of relatively little change are typified by an anticyclone under a broad, persistent ridge over the SEP, which is the case for most of November and more generally the summer months. Circulation is along the MBL height isopleths, minimizing advection and precluding large changes in MBL depth (Fig. 14a). Subtle changes in vertical velocity and the entrainment velocity may become more important in this case. Passage of a cyclone impacts the circulation and induces along-gradient components that rapidly change the MBL height. When ridging near the coast amplifies, the anticyclone shifts to the east and intensifies. A larger offshore wind component develops and advects the low MBL heights near the coast offshore (Fig. 14b). Depending on the duration of the anticyclone in this position, these lower heights may reach well offshore. As the trough and cyclone approach the coast of Chile (Fig. 14c), southeast wind is replaced by southwest wind. The generally higher height is advected from the south and the recovery of the MBL height occurs over a broad area. 

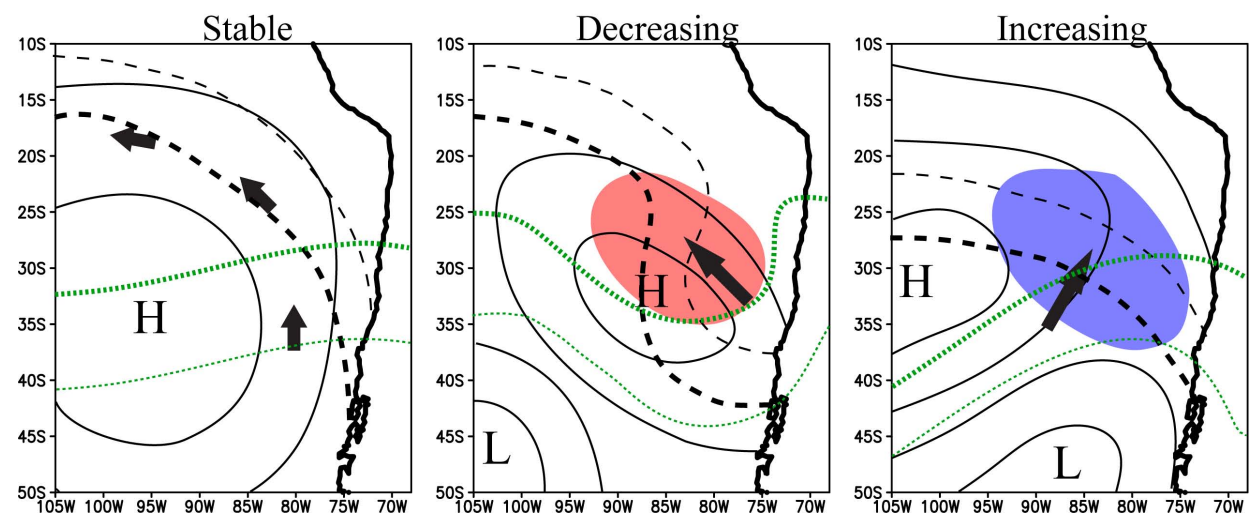

Fig. 14. Conceptual model of synoptic conditions during periods of stable, decreasing, and increasing MBL height. Solid contours indicate isobars with high and low pressure labeled. Black, dashed contours indicate isopleths of MBL depth for lower (thin) and higher (bold) height. Green, dotted contours indicate isopleths of 500-hPa height for lower (thin) and higher (bold) height. Vectors indicate low-level wind speed and direction. Decreasing (increasing) MBL heights indicated by red (blue) shading.

\section{Summary}

On average, the VOCALS-REx period (October-November 2008) was characterized by near normal conditions off northern Chile and southern Peru. Nevertheless, significant variations were observed during the first half of the campaign when midlatitude troughs reached the VOCALS-REx region. During this "disturbed" phase, the subsidence aloft was interrupted by periods of upward vertical velocity. In contrast, November exhibited more stable conditions and almost continuous subsidence over the VOCALS-REx region. Yet, this period featured the development of a coastal low off north-central Chile under a strong ridge aloft. This variable synoptic-scale environment translates into significant changes in MBL depth, which are documented and analyzed in this paper, and most likely other properties.

Day-to-day variations of MBL depth over the SEP during VOCALS-REx were investigated using primarily results from our WRF numerical simulation. The model setup and observations were described in Part 1 of this work (Rahn and Garreaud, 2009a). Simulated MBL depth compared most favorably to observations during October, but less so during November. Simulated MBL height tended to be lower than observations but the variation was similar. In the near coast region $\left(75-70^{\circ} \mathrm{W}\right)$ the zonal gradient in MBL depth is greater than observations, but the errors introduced by this bias are small during large synoptic changes and have a smaller impact for locations offshore, which were the focus of this study. Terms of the prognostic local MBL depth equation consisting of the horizontal advection of the MBL depth by the wind at the top of the MBL, large scale vertical velocity at the MBL top, and entrainment velocity are calculated from the model. Since entrainment velocity is not explicitly defined in the simulation, it is calculated as the residual of the other terms and hence their errors are propagated from the other terms into this term. While the majority of this term can be regarded as the entrainment velocity, it is acknowledged that this term contains other information. For this reason it is referred to as the residual term and not the entrainment velocity. To assess the relative contribution of each term in the MBL height equation, we examined time series at different locations, the instantaneous fields over the SEP at three relevant times, and a full sequence of MBL variation at Point Omega during VOCALS-REx. Our key findings are:

- As shown in other studies over the SEP (e.g., Wood and Bretherton, 2004) the average (time-mean) vertical velocity and residual are typically greatest in magnitude with opposing signs while the average advection is generally less.

- While the variation of vertical velocity is greater than advection in the north, advection dominates in the south mainly as a consequence of the greater synoptic variation at midlatitudes, some of which is translated to the north into the subtropics. The ratio of vertical velocity to advection along $20^{\circ} \mathrm{S}$, where many observations during VOCALS-REx took place, is between 1.25 and 2.

- The variability in advection and the rate of change of MBL depth is close over most of the domain with advection being almost twice as large. Indeed, time series at various points over the SEP indicated that the change of MBL depth depends greatly on the change in advection.

- Relative contributions of each term to changes in MBL depth were shown at individual times over the SEP during periods of rising, steady, and falling MBL height near Point Omega $\left(20^{\circ} \mathrm{S}, 85^{\circ} \mathrm{W}\right)$. These demonstrate the broad horizontal scale of the features as well as their instantaneous magnitude and collocation with changes in the MBL depth. 
- During events of large MBL depth changes (either positive or negative) around Point Omega, regions of large local MBL depth change were fairly well collocated with regions of strong advection of MBL depth, while the vertical velocity and residual play a less significant (but not entirely absent) role. On the contrary, during more quiescent periods, the advection field is significantly reduced. This leaves just the vertical velocity and residual to dictate the balance and results in more subtle changes in MBL depth.

Finally, we present a conceptual model linking midlatitude weather activity and large MBL variations over the subtropical SEP (represented by the MBL changes at Point Omega). When a midlevel ridge approaches the coast, the surface anticyclone strengthens and expands eastward, forcing offshore winds directed from low to high MBL height that rapidly lowers the MBL height over the open ocean. This result emphasizes the need to accurately represent the MBL near the coast (an unresolved issue by most numerical models, see Part 1) to properly simulate the MBL variations offshore. As the ridge crosses the Andes, a surface depression moves eastward and reaches the coast. In this stage, wind shifts to the southwest becoming directed from high to low MBL height and rapidly increases the MBL height at Point Omega. Characteristics of the MBL including how it redevelops after the passage of a midlatitude system may have important implications for the MBL in the subtropics.

Acknowledgements. This project was supported by FONDECYT Grant 1090412 and CONICYT Grant ACT-19/R-19. We are grateful to the numerous participates in VOCALS-REx that took observations. We would particularly like to thank David Painemal for providing the MODIS-derived MBL height at Point Omega and University of Wyoming personnel for providing radar-derived cloud top heights from the C-130 supported by NSF grant AGS-0715077.

Edited by: R. Wood

\section{References}

Barrett, B., Garreaud, R., and Falvey, M.: Impacts of the Andes cordillera on precipitation from a midlatitude cold front, Mon. Weather Rev., 137, 3092-3109, 2009.

Caldwell, P., Bretherton, C. S., and Wood, R.: Mixed-layer budget analysis of the diurnal cycle of entrainment in southeast Pacific stratocumulus, J. Atmos. Sci., 62, 3775-3791, 2005.

Garreaud, R., Rutllant, J., and Fuenzalida, H.: Coastal lows in north-central Chile: Mean structure and evolution, Mon. Weather Rev., 130, 75-88, 2002.

Garreaud, R. D. and Rutllant, J.: Coastal lows along the subtropical west coast of South America: Numerical simulation of a typical case. Mon. Weather Rev., 131, 891-908, 2003.

Garreaud, R. D. and Muñoz, R. C.: The diurnal cycle in circulation and cloudiness over the subtropical southeast pacific: A modeling study, J. Climate., 17, 1699-1710, 2004.

Garreaud, R. D. and Muñoz, R. C.: The low-level jet off the subtropical west coast of South America: Structure and variability, Mon. Weather Rev., 133, 2246-2261, 2005.

Leon, D. C., Wang, Z., and Liu, D.: Climatology of drizzle in marine boundary layer clouds based on 1 year of data from CloudSat and Cloud-Aerosol Lidar and Infrared Pathfinder Satellite Observations (CALIPSO), J. Geophys. Res., 113, D00A14, doi:10.1029/2008JD009835, 2008.

Lewis, J. M.: Use of a mixed-layer model to investigate problems in operational prediction of return flow, Mon. Weather Rev., 135, 2610-2628, 2007.

Lilly, D.: Models of cloud-topped mixed layers under a strong inversion, Q. J. Roy. Meteor. Soc., 94, 292-309, 1968.

Liu, Q., Lewis, J. M., and Schneider, J. M.: A study of cold-air modification over the Gulf of Mexico using in situ data and mixedlayer modeling, J. Appl. Meteorol., 31, 909-924, 1992.

Muñoz, R. C. and Garreaud, R. D.: Dynamics of the low-level jet off the west coast of subtropical South America, Mon. Weather Rev., 133, 3661-3677, 2005.

Rahn, D. A. and Garreaud, R. D.: Marine boundary layer over the subtropical southeast Pacific during VOCALS-REx. Part 1: Mean structure and diurnal cycle, Atmos. Chem. Phys., 10, 44914506, doi:10.5194/acp-10-4491-2010, 2010.

Skamarock, W. C., Klemp, J. B., Dudhia, J., Gill, D. O., Barker, D. M., Wang, W., and Powers, J. G.: A description of the advanced research WRF version 2, Tech. rep., NCAR, 88 pp., 2005.

Wood, R. and Bretherton, C. S.: Boundary layer depth, entrainment, and decoupling in the cloud-capped subtropical and tropical marine boundary layer, J. Climate, 17, 3576-3588, 2004.

Wood, R., Bretherton, C., Fairall, C., et al.: VOCALS Regional Experiment: Experimental design overview, available online at: http://www.atmos.washington.edu/ robwood/VOCALS/ VOCALS_EDO_Revised_April07.pdf, 2007

Zuidema, P., Painemal, D., de Szoeke, S., and Fairall, C.: Stratocumulus cloud-top height estimates and their climatic implications, J. Climate, 22, 4652-4666, 2009. 